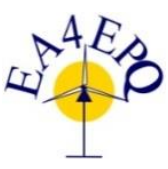

$19^{\text {th }}$ International Conference on Renewable Energies and Power Quality (ICREPQ’21) Almeria (Spain), $28^{\text {th }}$ to $30^{\text {th }}$ July 2021

Renemable Energy, and Ocumer Qualiin. Yournal (RE\&PQJ)

ISSN 2172-038 X, Volume No.19, September 2021

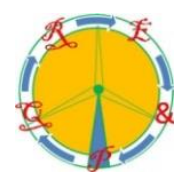

\title{
Design of a LLC Resonant Converter for Powering a PEM Electrolyzer
}

\author{
G. Vitale ${ }^{1}$, F. Castaldi ${ }^{2}$ and D. Guilbert ${ }^{3}$ \\ ${ }^{1}$ ICAR, Institute for high performance computing and networking, National Research Council of Italy, \\ via Ugo La Malfa 153, Palermo, Italy. Email: gianpaolo.vitale (at) car.cnr.it;
}

${ }^{2}$ Department of Engineering, University of Palermo, Viale delle Scienze, Palermo, Italy; castaldifabiola_94 (at) libero.it;

${ }^{3}$ Université de Lorraine, GREEN, F-54000 Nancy, France; damien.guilbert (at) univ-lorraine.fr;

\begin{abstract}
This paper proposes the design of a LLC resonant converter to supply a proton exchange membrane (PEM) electrolyzer. The PEM requires a low voltage with high current, a reduced output voltage ripple, and an overdamped dynamic behavior of the converter to avoid voltage overshoots. The designed converter allows satisfying the design constraints, minimizing switching and reverse recovery losses; the efficiency is influenced mainly by the output rectifier's conduction losses.
\end{abstract}

Key words. PEM electrolyzer; LLC converter, Zero Voltage Switching, energy efficiency.

\section{Introduction}

Hydrogen is the simplest element on Earth; it can be employed to store and deliver energy. Unfortunately, Hydrogen does not exist by itself in nature; hence it requires to be produced mainly by combining carbon (e.g., oil, natural gas) and with oxygen in water $\left(\mathrm{H}_{2} \mathrm{O}\right)[1,2]$.

The hydrogen produced by the electrolysis of water is still a small part representing only $4 \%$ of that obtained by fossil fuels (i.e., natural gas, oil) [3]. It is mainly due to the lower cost when fossil fuels are used. In fact, water electrolysis needs the use of electrolyzers that are quite expensive. On the other hand, the use of renewable energy sources (RES) to produce electric energy for water electrolysis allows environmentally friendly hydrogen production, known as green hydrogen [4,5].

There are three types of electrolyzers: Alkaline, proton exchange membrane (PEM), and solid oxide (SO) technologies; they differ for the electrolyte and ions transportation [3]. Alkaline and PEM technologies are available in the market; their supply needs a DC voltage (ranging from a few to hundreds of volt) and DC currents (from ten to thousands of amp). For this reason, a power converter is required [6,7]. In particular, when the supply is a power grid or a wind turbine, the AC/DC converters must be adopted; differently, solar panels can be interfaced with DC/DC converters. The use of power converters implies to study the current and voltage ripple effects both on the power supply side and on the electrolyzer side [711]. The literature highlighted the negative impact of current ripple from power electronics on the electrolyzers' specific energy consumption and energy efficiency [16,17].

Another challenge consists on the efficiency of the energy conversion process; to be competitive, the power converter should have the highest possible efficiency. It is a challenge considering that a high reduction ratio of the voltage is necessary since the electrolyzer requires a low voltage; thus, high currents have to be managed to reach the rated power.

To lessen switching losses, resonant converters, either in series (SRC) or in parallel (PRC) configuration, can be employed since they allow the commutation of the power switch with either the voltage or the current null. On the other hand, their operation is satisfactorily only near the resonant frequency, and the regulation suffers from light load conditions. Differently, LLC resonant converters, by exploiting the transformer's magnetizing inductance, are more flexible during operation even if the design is more complicated $[19,21]$.

The literature proposes several applications of LLC both for high and low power. As an example, [22] proposes a hybrid LLC resonant converter with three modes of operation for on-board chargers of electric vehicles, [23] exploits a three-level configuration for wide input voltage applications. In [24], the use of LLC converter is discussed as front-end for DC/DC converters whereas [25] proposes the use of LLC converter together with partial power conversion to achieve high step-down ratio; finally, in [26] a power supply for LED lighting based on LLC converter is proposed.

The use of an LLC converter has not yet been investigated to power an electrolyzer. In this case, some additional constraints, as the reduced output voltage ripple and the overdamped response have to be considered.

This paper proposes the design of a LLC converter for a proton exchange membrane (PEM) electrolyzer. This converter exploits resonance to minimize switching losses by zero voltage switching (ZVS) commutation of the power switches. The design is discussed concerning the load features, and considering a DC supply delivered by the single-phase power grid. 


\section{Main features of a PEM Electrolyzer}

The proton exchange membrane electrolyzers employ solid polymer electrolyte (SPE) to manage the protons' transfer from the anode to the cathode, the separation of the generated gas both at the anode and cathode, and the electrical insulation between both electrodes. The chemical reaction is the following:

$$
\begin{array}{lrl}
\text { Anode } & 2 \mathrm{H}_{2} \mathrm{O} \rightarrow \mathrm{O}_{2}+4 \mathrm{H}^{+} \\
+ & 4 e^{-} \\
& \text {Cathode } & 4 \mathrm{H}^{+}+4 e^{-} \\
& \rightarrow & 2 \mathrm{H}_{2} \\
\text { Global } & & 2 \mathrm{H}_{2} \mathrm{O} \\
& \rightarrow & 2 \mathrm{H}_{2}+\mathrm{O}_{2}
\end{array}
$$

Eq. (1) shows that into the anode, the water molecules are split into oxygen and positively charged protons. Then, protons pass through the SPE towards the cathode where, according to (2), they are combined with electrons coming from the power supply to make hydrogen. It should be underlined that, as a result of the global reaction, see eq. (3), only oxygen is obtained as a waste product, confirming the absence of pollution. The operation of a proton exchange membrane water electrolyzer is schematically shown in figure 1 .

The reaction described by (1) requires energy to be performed; it corresponds to Gibbs energy $\left(237 \mathrm{~kJ} \cdot \mathrm{mol}^{-1}\right)$, further energy is lost as heat (48.6 kJ.mol $\left.{ }^{-1}\right)$ [7, 27]. Finally, not all electrons delivered by the power supply will be converted into hydrogen; the phenomenon is described by Faraday efficiency [4, 28].

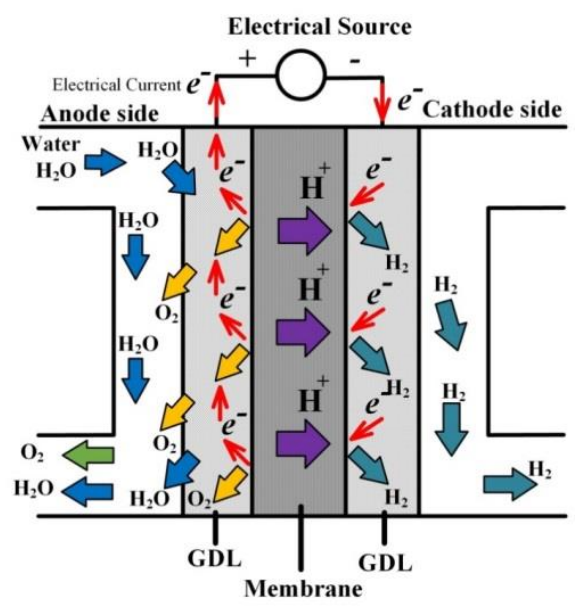

Fig.1. Operation principle for a PEM electrolyzer

\section{The electrolyzer under study}

The electrolyzer to be supplied by the proposed converter is the model QL-300 PEM Hydrogen Generator produced by Fuel Cell Store (Product Code: 1021882). It uses SPE/PEM technology to produce hydrogen with high purity (99.999\%). The QL-300 shows an output pressure rate ranging up to $310 \mathrm{ml} / \mathrm{min}$ and requires an input power of $150 \mathrm{~W}$. The standard configuration is supplied by the grid by a converter given by manufacturer; however for this research purpose, it has been delivered without the power supply. The maximum voltage required at the input terminals is equal to $5 \mathrm{~V}$ (corresponding to a $\mathrm{DC}$ current of about 45A). A photograph of the electrolyzer is shown in figure 2.

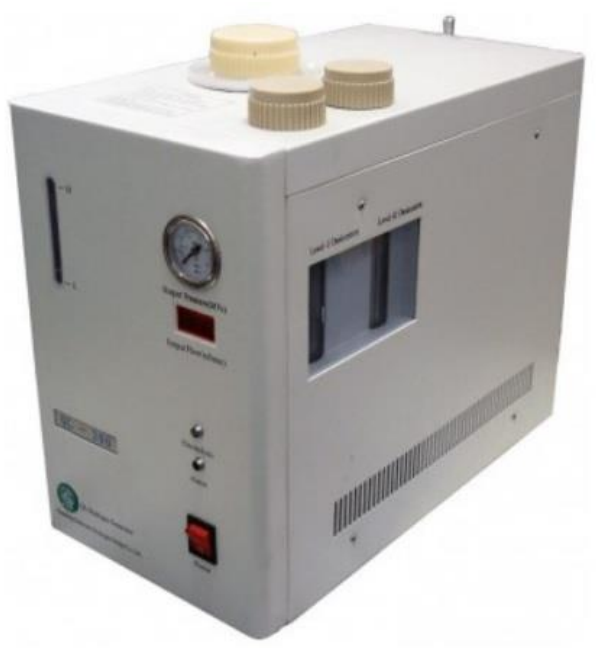

Fig.2. External view of the QL-300 electrolyzer

\section{The LLC resonant half-bridge converter}

The designed circuit chosen to supply the electrolyzer is a resonant LLC converter in half-bridge configuration as in [18]. The electric scheme is shown in figure 3.

Three main parts can be recognized: the half-bridge, the resonant circuit, and the converter's secondary side.

\section{A. The half-bridge}

The half-bridge aims to give a unipolar square-wave voltage. It is formed by two MOSFETs driven with a $50 \%$ duty cycle. A dead time between two consecutive transitions allows both to avoid cross-conduction and achieve the ZVS condition to minimize switching losses.

\section{$B$. The resonant circuit.}

The resonant circuit is formed by a resonant capacitance and two inductors. The former inductor is a discrete component, whereas the latter is obtained by exploiting the transformer's magnetizing inductance. The resonant circuit is interposed between the half-bridge and the load. The resonant current allows both delivering energy to the transformer and obtain ZVS. The transformer lessens the $\mathrm{AC}$ voltage and assures galvanic insolation.

\section{The secondary side}

The transformer output voltage is converted into DC voltage by a full-wave rectifier with a centre tap configuration. An output capacitor minimizes the voltage ripple before supplying the electrolyzer.

\section{Operating principle}

A traditional series resonant converter (SRL) exhibits a minimum impedance at the resonant frequency. Due to this selective property, the impedance is much higher far from the resonant frequency. 


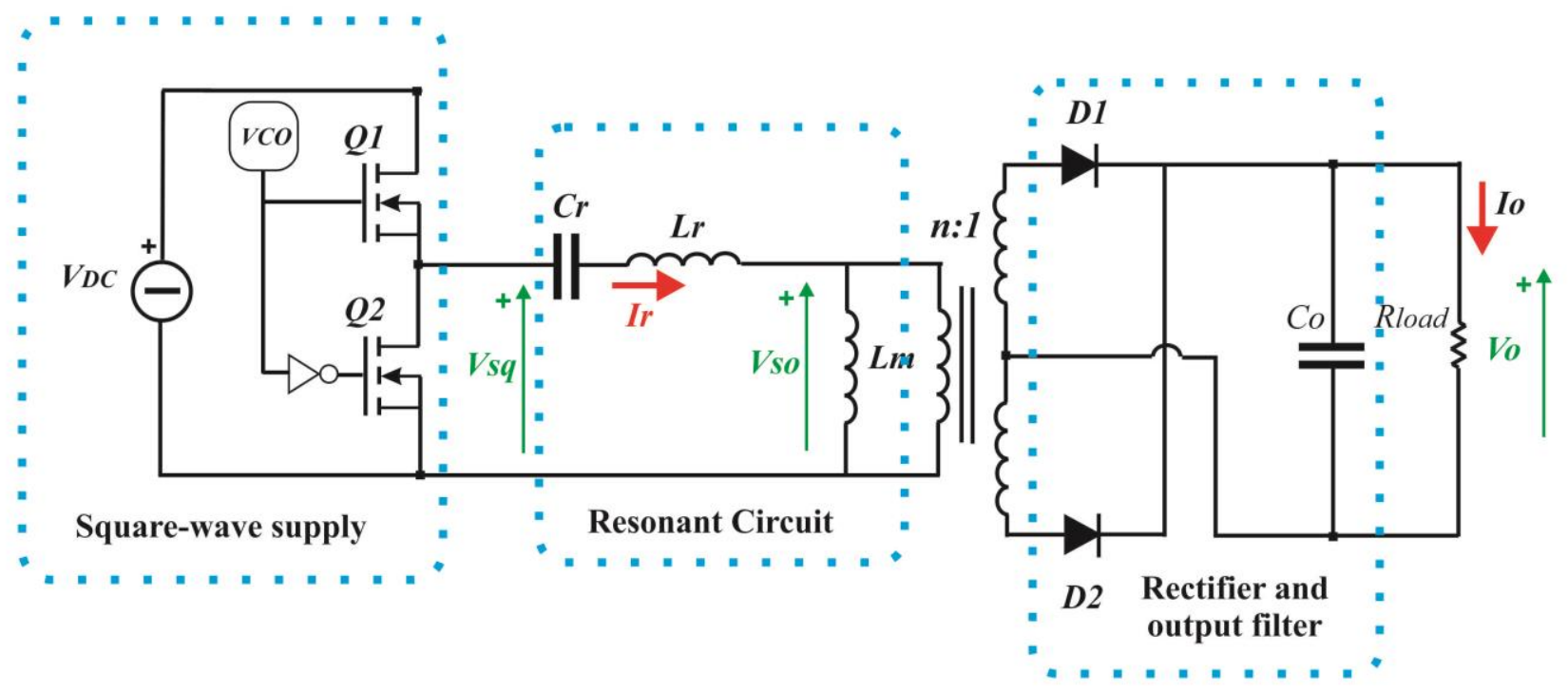

Fig.3 Electric scheme of the LLC resonant converter

The amount of current that can be delivered to the load depends both on the resonant circuit's impedance at the frequency of the square wave supply and on the load's impedance. As a consequence, a wide input frequency variation is required to compensate for input and output variations.

In a LLC converter, there are two characteristic frequencies: the former, $f o$, is equal to the resonant frequency of a SRC and corresponds to the one defined by the inductor and capacitor $L_{r}$ and $C_{r}$, respectively, as in (1); the latter, $f p$, takes into consideration the contribution of the magnetizing inductance of the transformer $L_{m}$ as in (2).

$$
\begin{gathered}
f_{o}=\frac{1}{2 \pi \sqrt{L_{r} C_{r}}} \\
f_{p}=\frac{1}{2 \pi \sqrt{\left(L_{r}+L_{m}\right) C_{r}}}
\end{gathered}
$$

As the load is varied, the resonance frequency, fco, ranges from $f p$ to $f o$. Particularly, at no load $f c o=f p$ whereas in a short circuit condition, $f c o=f o$. This feature allows to define a family of curves within the range $f p \leq f c o \leq f o$; on the other hand, the design procedure is more complicated.

As concerns the design, the parameters of interest are: the voltage across the MOSFETs that should be as low as possible during commutation to achieve the ZVS, the resonant and the magnetizing current of the transformer, and the current flowing through the diodes of the output rectifier.

When the switching frequency is equal to $f o$, as soon as Q1 is turned off, the resonant current equals the magnetizing current, there is no power transfer to the load, and with a suitable delay of Q2 turn on, the ZVS condition can be achieved. When the switching frequency is below fo, the ZVS can still be achieved together with a soft commutation of the diodes D1 and D2 occurring at zero current. Since these diodes operate in discontinuous mode, a higher current will circulate in the resonant circuit to guarantee the energy balance to the load and, consequently, higher conduction losses in the primary and secondary circuit will occur.

Finally, When the switching frequency is higher than fo, a smaller circulating current will be present both in the primary and secondary circuit, reducing conduction losses, but the rectifier diodes will suffer reverse recovery losses since they are not softly commutated. The ZVS condition for MOSFETs can still be achieved.

The LLC converter's design is performed to operate in the neighbourhood of fo and exploits a suitable gain function defined based on the converter's parameters. To calculate the transfer function, the first approximation method (FHA) can be adopted. Under the hypothesis that the converter is operated near fo, the current flowing the resonant circuit can be approximated as purely sinusoidal. In this way, instead of the equivalent circuit of the LLC shown in figure $4 \mathrm{a}$, the linear sinusoidal circuit shown in figure $4 \mathrm{~b}$ can be adopted, where $V g e$ is the fundamental component of $V s q$ supplying the circuit of figure $4 \mathrm{~b}$ and Voe the fundamental component of Vso. Based on FHA, the transfer function and the gain of the converter can be defined as:

$$
M_{g_{-} D C}=\frac{V_{o} \cdot n}{V_{D C} / 2}
$$

Where $n$ is the turn ratio of the transformer, $\mathrm{V}_{\mathrm{DC}}$ and $\mathrm{Vo}$ are the input and output DC voltage, respectively. From the circuit of figure $4 b$, the DC values of $V_{D C}$ and $V_{0}$ can be substituted with the RMS values:

$$
M_{g_{-} D C}=\frac{V_{o} \cdot n}{V_{D C} / 2} \approx M_{g_{-} s w}=\frac{V_{s o}}{V_{s q}} \approx M_{g_{-} A C}=\frac{V_{o e}}{V_{g e}}
$$

Finally the gain can be calculated: 


$$
M_{g_{-} D C}=\frac{V_{o e}}{V_{g e}}=\left|\frac{\left(j \omega L_{m}\right) \| R_{e}}{\left(j \omega L_{m}\right) \| R_{e}+j \omega L_{r}+\frac{1}{j \omega C_{r}}}\right|
$$

Eq. (4) gives the output voltage by the knowledge of $\mathrm{Mg}$, $\mathrm{n}$, and Vin.
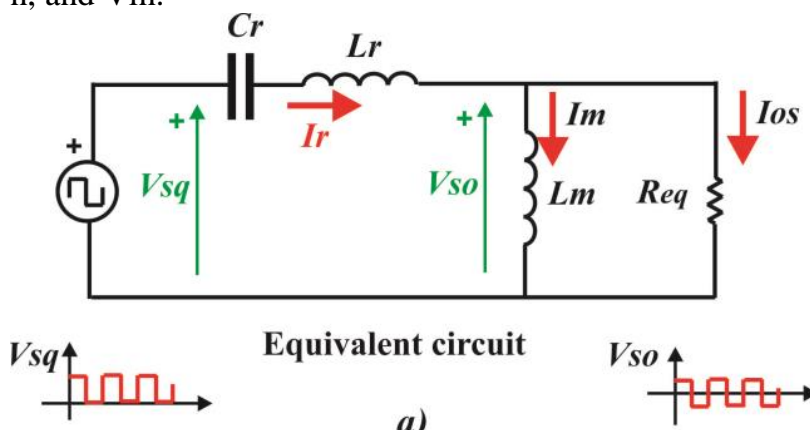

Equivalent circuit

a)
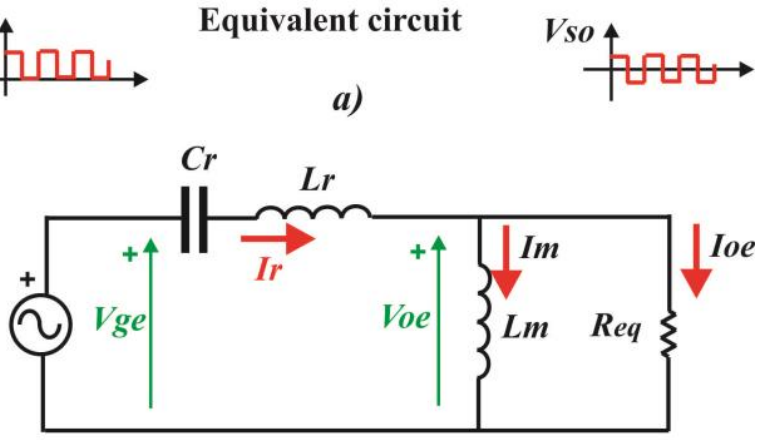

FHA equivalent circuit

b)

Fig. 4. a) equivalent circuit of the LLC converter, b) FHA circuit model of the LLC converter

It is more convenient to adopt normalized quantities to describe eq. (5) considering: $f_{n}$ as the ratio between the witching and the resonant frequency, $L_{n}$ as the ratio between the magnetizing and resonant inductance, and a quality factor $Q_{e}$.

$$
\begin{gathered}
f_{n}=\frac{f_{s w}}{f_{o}} \\
L_{n}=\frac{L_{m}}{L_{r}} \\
Q_{e}=\frac{\sqrt{L_{r} / C_{r}}}{R_{e}}
\end{gathered}
$$

In this way, eq. (5) becomes:

$$
=\left|\frac{L_{n} \cdot f_{n}^{2}}{\left[\left(L_{n}+1\right) \cdot f_{n}^{2}-1\right]+j\left[\left(f_{n}^{2}-1\right) \cdot f_{n} \cdot Q_{e} \cdot L_{n}\right]}\right|
$$

And the output voltage is given by:

$$
V_{o}=M_{g} \cdot \frac{1}{n} \cdot \frac{V_{D C}}{2}
$$

The transfer function $M g$ can be drawn versus frequency with $L n$ and $Q e$ as parameters.

\section{Design of the LLC resonant converter}

A. Design constraints

The constraints for the converter design are the following:

- Input voltage: $\left(300-320 \mathrm{~V}_{\mathrm{DC}}\right)$;

- Rated power: $225 \mathrm{~W}$;

- Output voltage range (3-5 V);

- Maximum output current: 45 A (in correspondence of $5 \mathrm{~V}$ of voltage output;

- Output Voltage line regulation $\leq 1 \%$ (Vin=320 V);

- Output voltage ripple $\leq 120 \mathrm{mV}$ :

- Switching frequency (100-150kHz).

The input voltage is supposed as delivered by a full-wave rectifier supplied by a single-phase grid; it corresponds to about $300-320 \mathrm{~V}_{\mathrm{DC}}$. The rated power is provided at a current of $45 \mathrm{~A}$ when the voltage is $5 \mathrm{~V}$. A small output of the voltage ripple is required to preserve the electrolyzer; for this reason, the switching frequency is chosen higher than $100 \mathrm{kHz}$; besides, it allows a suitable highfrequency transformer to be adopted. It should be underlined that the load is modelled as a purely resistive one; the complete model shown in [27] would require the dynamic behaviour as well; however, since it influences only transients, the steady-state analysis can be performed satisfactorily with the simplified approach.

\section{B. Choice of the components}

The design has been performed by the steps described in [18]. The following parameters are chosen: $\mathrm{Ln}=5$ and $\mathrm{Qe}=0.35$, it guarantees a good linear regulation interval. With these parameters, the gain curve shown in figure 5 has been obtained. It can be noted that the gain decreases linearly with the frequency in the operating interval 110$150 \mathrm{kHz}$. The resonance frequency is set equal to 130 $\mathrm{kHz}$. The adopted switching frequency also makes easier the filtering design to avoid EMI [29].

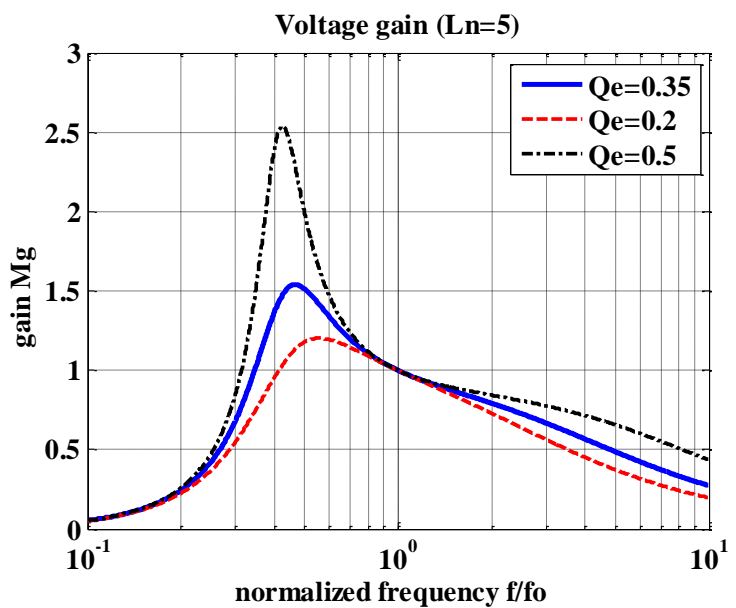

Fig. 5. Normalized gain of the converter vs, frequency 
The list of the adopted components is given in table 1 . It should be noted that the output capacitor has been obtained by a parallel connection to reduce the ESR and the related losses. The high frequency transformer is wounded on the specified core to obtain the requested reduction ratio.

Table 1: list of the components

\begin{tabular}{|c|c|c|c|}
\hline Symbol & $\begin{array}{l}\text { Rated } \\
\text { value }\end{array}$ & Supplier & Code \\
\hline $\begin{array}{l}\text { MOSFET } \\
(\mathrm{x} 2)\end{array}$ & $\begin{array}{l}650 \mathrm{~V} \\
5.5 \mathrm{~A}\end{array}$ & Infineon & IPP65R420CFD \\
\hline $\begin{array}{l}\text { Diode } \\
(\mathrm{x} 2)\end{array}$ & $\begin{array}{l}0.79 \mathrm{~V} \\
70 \mathrm{~A}\end{array}$ & IXYS & DSA70C $200 \mathrm{HB}$ \\
\hline $\mathrm{Lr}$ & $39 \mu \mathrm{H}$ & Bourns & $\begin{array}{c}\text { 2100LL-390- } \\
\text { RC }\end{array}$ \\
\hline $\mathrm{Cr}$ & $38 \mathrm{nF}$ & Wurth & $\begin{array}{l}\text { WCAP-FTXX } \\
\text { Film Capacitor }\end{array}$ \\
\hline Co (x9) & $100 \mu \mathrm{F}$ & KEMET & $\begin{array}{c}\text { C1006-X5R- } \\
\text { SMD }\end{array}$ \\
\hline Transformer & 19:1:1 & TDK-Epcos & PQ35/35 core \\
\hline VCO & & LT & LTC6990 \\
\hline Driver & & $\mathrm{LT}$ & LT1162 \\
\hline
\end{tabular}

\section{Results}

Results are obtained by LTspice simulator; they show the behaviour of the converter at $110 \mathrm{kHz}, 130 \mathrm{kHz}$ and 150
$\mathrm{kHz}$, respectively. Figure 6 shows the input current (top view) and the output voltage (bottom view). It can be noted that the output voltage ranges from $4.5 \mathrm{~V}$ to $2.64 \mathrm{~V}$ with a ripple of about $1 \%$. Figure 7 shows the current through the diodes of the rectifier I(D2), I(D3) (top view), and the resonant current $I r$ with the magnetizing current Im (bottom view). All currents decrease increasing the switching frequency as expected. It can be appreciated the soft commutation of the diodes occurring at zero current as shown by the zoom of the same currents of figure 8 also above the resonant frequency. Finally, figure 9 shows the drain-source voltage of the MOSFET Q2 (top view) and the voltage applied to the gate of the MOSFETs (bottom view) where it can be noted that the dead time assures the ZVS commutation.

The dynamic behaviour of the converter has been verified by a step variation of the control frequency. Figure 10 and 11 shows the output voltage when a step variation from $140 \mathrm{kHz}$ to $120 \mathrm{kHz}$ and vice versa is imposed to the control frequency. In any case, the converter shows a overdamped behaviour as required; this lack of overvoltage due to oscillations is important to preserve the electrolyzer.

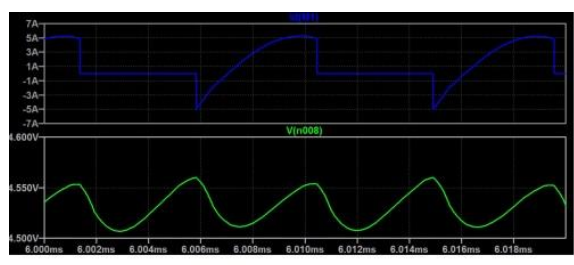

$\mathrm{fs}=110 \mathrm{kHz}$

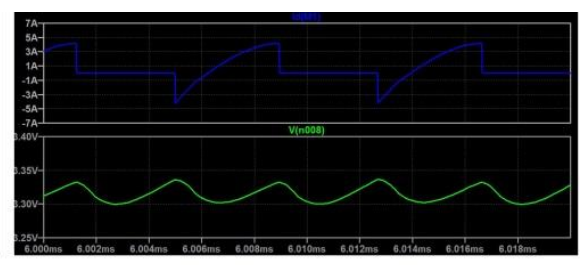

$\mathrm{fs}=130 \mathrm{kHz}$

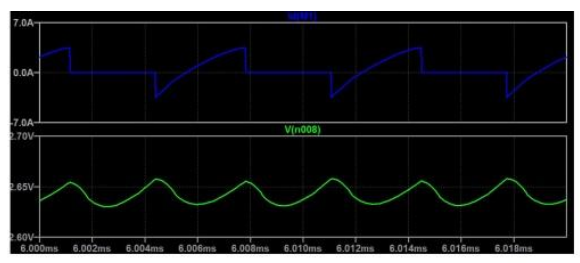

$\mathrm{fs}=150 \mathrm{kHz}$

Fig. 6. Input current (top view) and output voltage (bottom view)

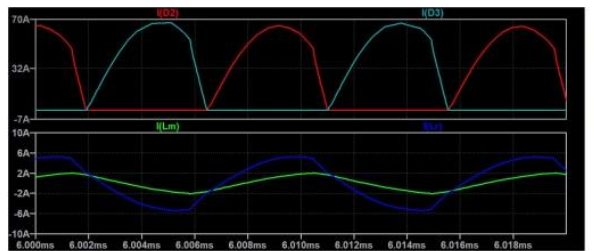

fs $=110 \mathrm{kHz}$

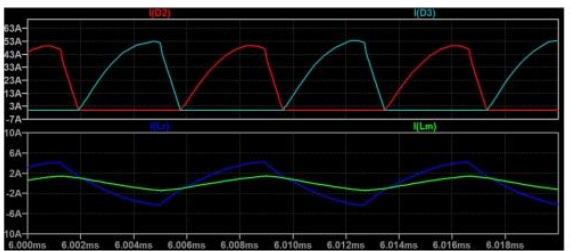

fs $=130 \mathrm{kHz}$

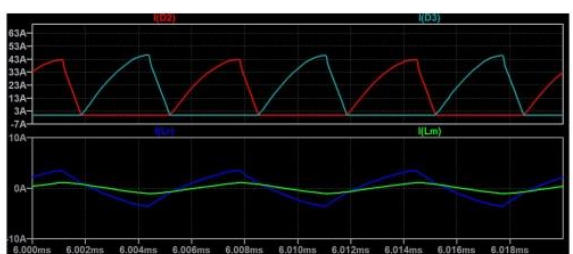

$\mathrm{fs}=150 \mathrm{kHz}$

Fig. 7. Current through the rectifier diodes (top view) and resonant with magnetizing current (bottom view)

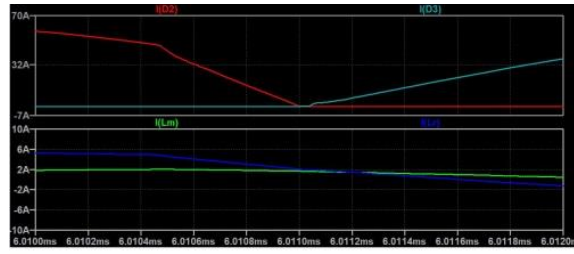

fs $=110 \mathrm{kHz}$

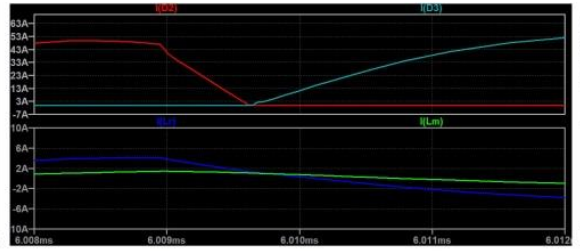

fs $=130 \mathrm{kHz}$

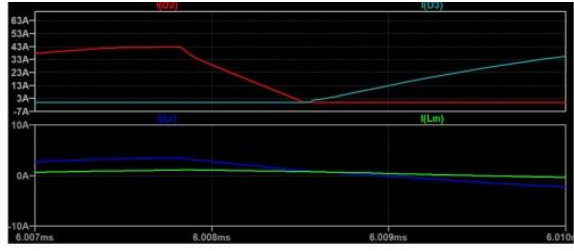

$\mathrm{fs}=150 \mathrm{kHz}$

Fig. 8. Zoom of figure 7 to show the soft commutation of the diodes

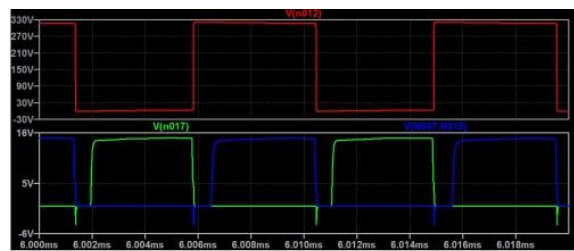

fs $=110 \mathrm{kHz}$

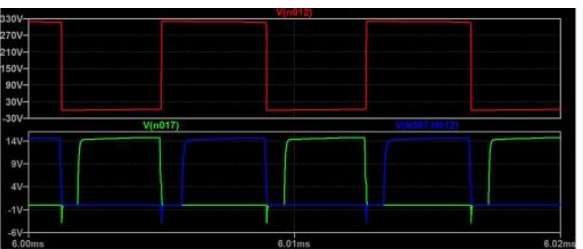

fs $=130 \mathrm{kHz}$

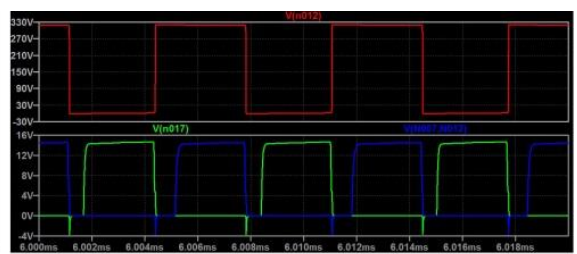

fs $=150 \mathrm{kHz}$

Fig. 9.Drain-to-Source voltage of the MOSFET Q2 (top view) and gate voltage (bottom view) 
Besides, since the dynamic response can be approximated by a dominant pole, the feedback performed by a PI regulator will be able to maintain the overdamped response.

The efficiency of the converter has been calculated considering switching and conduction losses on the two MOSFETs, conduction losses on Diodes, Joule losses on inductor $\mathrm{Lr}$, capacitor $\mathrm{Cr}$ and capacitor $\mathrm{Co}$, joule and magnetic losses in the transformers (this last contribution in negligible). Losses are shown in figure 12 versus the output power. Finally, the overall efficiency vs. the output power is shown in figure 13. It can be noted that a relevant amount of losses is due to the conduction losses of the diodes that are subjected to high currents. A further optimization could be performing by a synchronous rectifier; it would allow to halve these losses and to raise the efficiency up to about $75 \%$ at rated power.

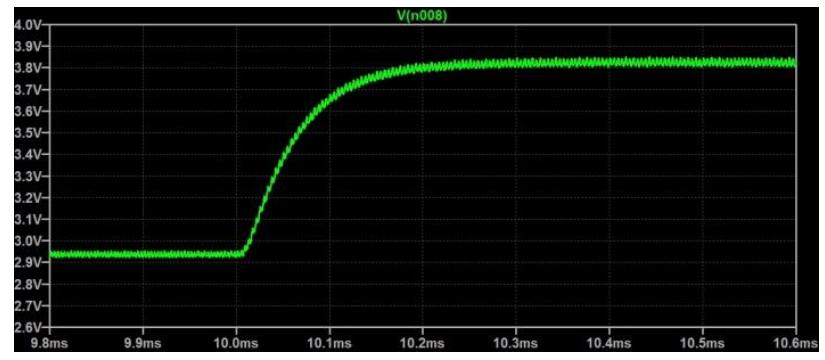

Fig. 10. Output voltage with a step variation of the input frequency from $140 \mathrm{kHz}$ to $120 \mathrm{kHz}$.

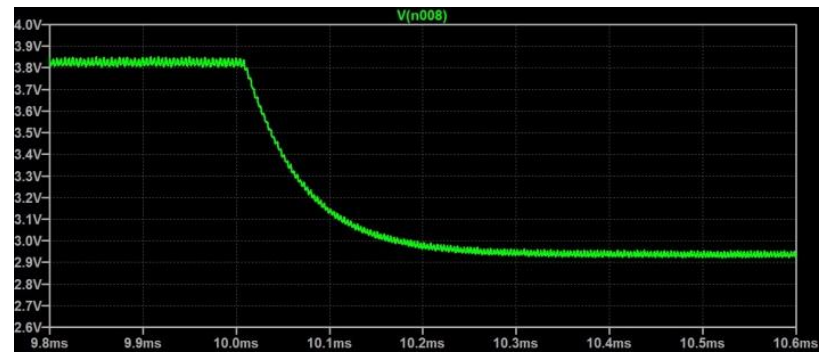

Fig. 11. Output voltage with a step variation of the input frequency from $120 \mathrm{kHz}$ to $140 \mathrm{kHz}$.

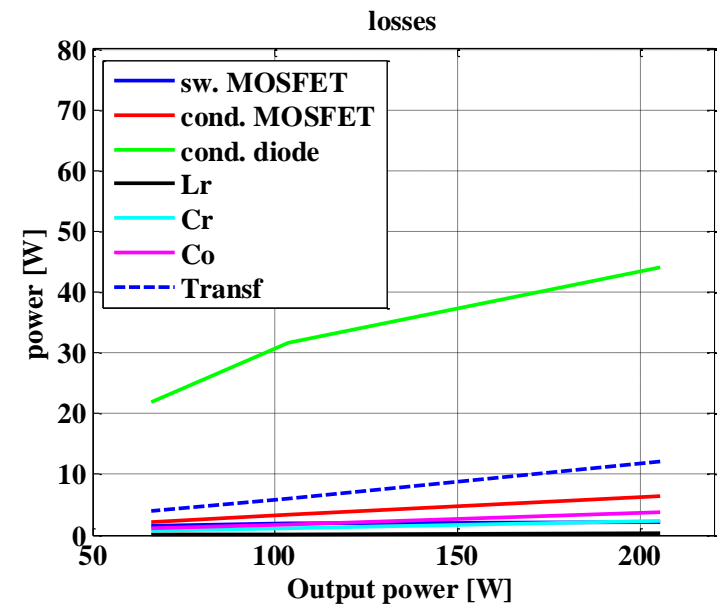

Fig. 12. Losses vs. frequency of the converter's components

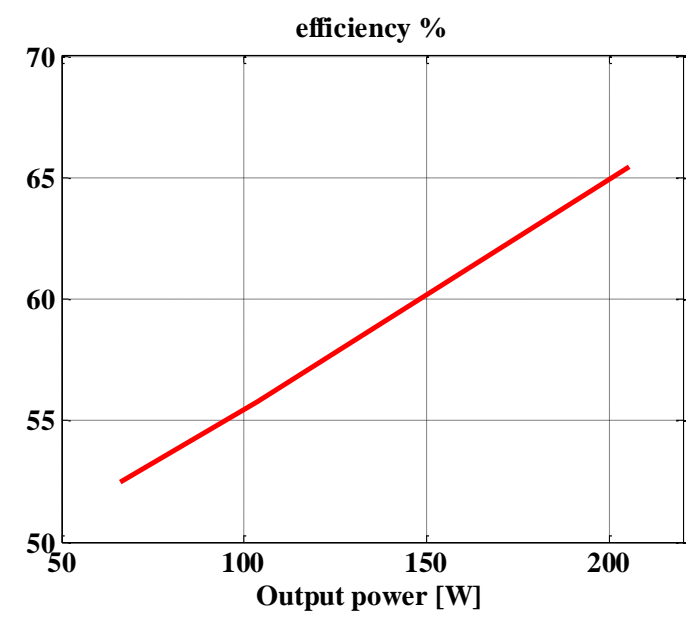

Fig. 13. Efficiency vs. output power of the converter.

\section{Conclusion}

A LLC resonant converter has been designed to supply a PEM electrolyzer. The converter allows a high voltage reduction ratio minimizing the overall stress of the MOSFETs. It also guarantees the voltage regulation in the operating range of the electrolyzer, a reduced output voltage ripple and an overdamped dynamic response. This topology allows minimizing losses switching and reverse recovery losses; the efficiency is reduced mainly by conduction losses on the rectifier due to the high output current.

\section{References}

[1] Nikolaidis, P.; Poullikkas, A. A comparative overview of hydrogen production processes. Renew. Sustain. Energy Rev. 2017, 67, 597-611.

[2] Yodwong, B., Guilbert, D., Phattanasak, M., Kaewmanee, W., Hinaje, M., \& Vitale, G. (2020). Proton Exchange Membrane Electrolyzer Modeling for Power Electronics Control: A Short Review. C-Journal of Carbon Research, 6(2), 29.

[3] Hiva Kumar, S.; Himabindu, V. Hydrogen production by PEM water electrolysis-A review. Mater. Sci. Energy Technol. 2019, 2, 442-454.

[4] Carmo, M.; Fritz, D.; Mergel, J.; Stolten, D. A comprehensive review on PEM water electrolysis. Int. J. Hydrogen Energy 2013, 38, 4901-4934.

[5] Falcão, D.; Pinto, A. A review on PEM electrolyzer modelling: Guidelines for beginners. J. Clean. Prod. 2020, 261, 121184 .

[6] Yodwong, B., Guilbert, D., Phattanasak, M., Kaewmanee, W., Hinaje, M., \& Vitale, G. (2020). AC-DC converters for electrolyzer applications: State of the art and future challenges. Electronics, 9(6), 912.

[7] Solanki, J.; Wallmeier, P.; Böcker, J.; Averberg, A.; Fröhleke, N. High-current variable-voltage rectifiers: State of the art topologies. IET Power Electron. 2015, 8, 1068-1080.

[8] Solanki, J.; Fröhleke, N.; Böcker, J.; Wallmeier, P. Comparison of Thyristor-Rectifier with Hybrid Filter and Chopper-Rectifier for High-Power, High-Current Application. 
In Proceedings of the PCIM Europe, Nuremberg, Germany, 1416 May 2013; pp. 1391-1398.

[9] Rodriguez, J.; Pontt, J.; Silva, C.; Wiechmann, E.; Hammond, P.; Santucci, F.; Alvarez, R.; Musalem, R.; Kouro, S.; Lezana, P. Large Current Rectifiers: State of the Art and Future Trends. IEEE Trans. Ind. Electron. 2005, 52, 738-746.

[10] Solanki, J.; Frohleke, N.; Bocker, J. Implementation of Hybrid Filter for 12-Pulse Thyristor Rectifier Supplying HighCurrent Variable-Voltage DC Load. IEEE Trans. Ind. Electron. $2015,62,4691-4701$

[11] Koponen, J.; Ruuskanen, V.; Kosonen, A.; Niemela, M.; Ahola, J. Effect of Converter Topology on the Specific Energy Consumption of Alkaline Water Electrolyzers. IEEE Trans. Power Electron. 2019, 34, 6171-6182.

[16] Dobó, Z.; Palotás, Á. Impact of the current fluctuation on the efficiency of Alkaline Water Electrolysis. Int. J. Hydrogen Energy 2017, 42, 5649-5656.

[17] Ruuskanen, V.; Koponen, J.; Kosonen, A.; Niemelä, M.; Ahola, J.; Hämäläinen, A. Power quality and reactive power of water electrolyzers supplied with thyristor converters. J. Power Sources 2020, 459, 228075.

[18] Topic Category: Design Reviews - Functional Circuit locks, "Designing an LLC Resonant Half-Bridge Power Converter", available on:

https://www.ti.com/seclit/ml/slup263/slup263.pdf (accessed on March the $\left.9^{\text {th }}, 2021\right)$.

[19] Jung, J. H., \& Kwon, J. G. (2007, September). Theoretical analysis and optimal design of LLC resonant converter. In 2007 European Conference on Power Electronics and Applications (pp. 1-10). IEEE.

[20] Hillers, A., Christen, D., \& Biela, J. (2012, September). Design of a highly efficient bidirectional isolated LLC resonant converter. In 2012 15th International Power Electronics and Motion Control Conference (EPE/PEMC) (pp. DS2b-13). IEEE.

[21] Qiu, Y., Liu, W., Fang, P., Liu, Y. F., \& Sen, P. C. (2018, March). A mathematical guideline for designing an AC-DC LLC converter with PFC. In 2018 IEEE Applied Power Electronics Conference and Exposition (APEC) (pp. 2001-2008). IEEE.

[22] Dao, N. D., \& Lee, D. C. (2020). High-efficiency hybrid LLC resonant converter for on-board chargers of plug-in electric vehicles. IEEE Transactions on Power Electronics, 35(8), 83248334.

[23] Saravanan, S., Mohan, J., \& Kumar, V. (2014). Analysis of a three-level LLC series resonant converter for high-and wideinput-voltage applications. J. Eng. Res. Appl., 4(4), 79-84.

[24] Liu, F., Ruan, X., Huang, X., \& Qiu, Y. (2019). Second harmonic current reduction for cascaded inverter with preregulator+ LLC converter as front-end dc-dc converter. In 2019 IEEE Energy Conversion Congress and Exposition (ECCE) (pp. 686-690). IEEE.

[25] Chen, L., Wu, H., Xu, P., Hu, H., \& Wan, C. (2015, March). A high step-down non-isolated bus converter with partial power conversion based on synchronous LLC resonant converter. In 2015 IEEE Applied Power Electronics Conference and Exposition (APEC) (pp. 1950-1955). IEEE.
[26] Ma, W., Xie, X., \& Jiang, S. (2017, March). LLC resonant converter with variable resonant inductor for wide LED dimming range. In 2017 IEEE Applied Power Electronics Conference and Exposition (APEC) (pp. 2950-2957). IEEE.

[27] Guilbert, D., \& Vitale, G. (2019). Dynamic emulation of a pem electrolyzer by time constant based exponential model. Energies, 12(4), 750.

[28] Yodwong, B., Guilbert, D., Phattanasak, M., Kaewmanee, W., Hinaje, M., \& Vitale, G. (2020). Faraday's Efficiency Modeling of a Proton Exchange Membrane Electrolyzer Based on Experimental Data. Energies, 13(18), 4792.

[29] Giglia, G., Ala, G., Di Piazza, M. C., Giaconia, G. C., Luna, M., Vitale, G., \& Zanchetta, P. (2018). Automatic EMI filter design for power electronic converters oriented to high power density. Electronics, 7(1), 9.

\section{Authors' contributions:}

Conceptualization, G.V. and F.C.; methodology, G.V.; software, F.C.; validation, G.D., F.C. and G.V.; investigation, G.V.; data curation, F.C.; writing-original draft preparation, G.V.; writing-review and editing, D.G and G.V.; supervision, G.V.

All authors have read and agreed to the published version of the manuscript.

\section{Highlights of the paper}

Purpose of the paper: To design a power converter with high step-down ratio (about 100:1) to supply a PEM electrolyzer.

Methodology: The paper proposed a LLC converter where resonance is exploited to minimize switching losses and diodes reverse recovery losses.

Findings: The research shows that losses can be reduced in a wide interval of frequency by the LLC converter assuring an overdamped dynamic behavior.

Research limits: The electrolyzer is modelled neglecting its dynamic behaviour; it does not affect the design of the power circuit but can influence the control design. The efficiency is worsened by conduction losses on the rectifier diodes.

Practical implications: The use of more efficient converters can encourage the use of hydrogen also for low power.

Originality of the paper: It is the first time that a LLC power converter is proposed and discussed for a PEM electrolyzer. 